\title{
EFFECT OF GAMMA IRRADIATION ON ANTIOXIDANT POTENTIAL AND BIOACTIVES OF A COSMECEUTICALLY SIGNIFICANT CHLORELLA EMERSONII KJ725233
}

\author{
SNEHA SAWANT DESAI ${ }^{1}$, REEMA DEVI SINGH ${ }^{2}$, SUKHENDU GHOSH ${ }^{2}$, VARSHA KELKAR MANE1 ${ }^{*}$ \\ 1Department of Biotechnology, University of Mumbai, Kalina, Santacruz (E), Mumbai, Maharashtra, India 400098, ${ }^{2}$ Nuclear Agriculture \\ and Biotechnology Division, Bhabha Atomic Research Center, Trombay, Mankhurd, Mumbai, Maharashtra, India 400085 \\ Email: drvkelkar@mu.ac.in
}

Received: 20 Mar 2019 Revised and Accepted: 15 Jul 2019

\section{ABSTRACT}

Objective: Gamma radiation induces free radicals with a corresponding alteration in the cell's antioxidant defense system. The present study thus aimed at determining the role of gamma irradiation in improving the cosmeceutical potential of CEK in terms of antioxidants.

Methods: C. emersonii KJ725233 (CEK) was subjected to low (100 Gy) and high (1000 Gy) doses of gamma irradiation. The effect of such gamma radiation doses on the chlorophyll content was evaluated. The quantitative alterations in the antioxidant content of CEK were evaluated by phosphomolybdenum assay (TAC), ferric reducing antioxidant potential (FRAP), 2, 2-Dipheny-1-picryl hydrazyl radical scavenging assay (DPPH), total phenolic (TPC) and total flavonoid content (TFC). Also, the corresponding qualitative alterations in the bioactives of $C E K$ were determined by GC-HRMS analysis.

Results: A $179.57 \pm 2.55 \%$ increase in the total chlorophyll content along with a $71.76 \pm 2.96 \%, 32.08 \pm 2.16 \%, 11.67 \pm 0.89 \%, 42.85 \pm 8.0 \%$ and $31.37 \pm 3.18 \%$ increase was observed in the TAC, FRAP, DPPH radical scavenging, TPC and TFC respectively in CEK irradiated at 1000 Gy. GC-HRMS analysis revealed the induction of Vitamin E on irradiation at both the doses with a corresponding decrease in the phytol content, whereas $100 \mathrm{~Gy}$ stimulated the induction of phytosterols.

Conclusion: The potent intrinsic antioxidant activity of cosmeceuticals significant $C E K$ can be elevated with the induction of the most sought after antioxidant in cosmetology-Vitamin $\mathrm{E}$ as a response to irradiation.

Keywords: Gamma irradiation, C. emersonii KJ725233, Antioxidant, Vitamin E, Cosmeceutical

(C) 2019 The Authors. Published by Innovare Academic Sciences Pvt Ltd. This is an open-access article under the CC BY license (http://creativecommons.org/licenses/by/4.0/) DOI: http://dx.doi.org/10.22159/ijpps.2019v11i8.33153

\section{INTRODUCTION}

Cultural milieus such as the temperature, light intensity, photoperiod, irradiation and $\mathrm{pH}$ are known to impact the growth and subsequently the biochemical composition of microalgae [1]. Under such constraints, microalgae are reported to produce a maximal amount of varied bioactives as compared to normal conditions due to the stressed altered metabolic pathways. The induction or overproduction of these bioactives is primarily a survival technique to overcome the inconsiderate growth environments [2]. It is thus, necessary to manipulate the growth conditions in order to stimulate the synthesis of commercially significant microalgal bioactives [3].

Water that makes up $70-90 \%$ of the cell contents is the chief target of ionizing radiations. Water molecules are ionized into $\mathrm{H}_{2} \mathrm{O}$ - alongwith $\mathrm{H} \cdot$ and. $\mathrm{OH}$ which further generate the peroxyl and superoxide radicals $[4,5]$. As a result, the cell's antioxidant defense systems have to be modified to balance the detrimental effects of the free radicals generated $[6,7]$. Gamma irradiation with $\mathrm{Co}_{60}(1.33 \mathrm{MeV})$ has an ability to induce cytological, anatomical, biochemical, morphological and physiological alterations in cells and tissues [8-11].

The cosmetic industry has been leveraging on algae as a source of bio-sustainable ingredients as they are rich in biologically active components that are cost-effective. Such compounds meet consumer demands of being "natural" as well as "healthy" as compared to their synthetic counterparts. Some of the bioactives associated with skincare are the algal proteins, lipids, vitamins and secondary metabolites such as phenolics, hydrocarbons, pigments etc [12].

Effect of gamma radiations on Chlorella has been reported in terms of changes in the rates of respiration and photosynthesis, colony-forming ability, modulation of cell division and DNA synthesis [13]. The sensitivity of Chlorella to ionizing radiations depends on several factors, including the DNA content per cell and the stage of the cell cycle [14].
C. emersonii KJ725233 is a novel, non-fastidious microalga which is an antioxidant reserve isolated from the western regions of Maharashtra. The alga has been identified both morphologically as well as by $18 \mathrm{~s}$ rDNA sequencing $[15,16]$. The alga contains a plethora of compounds such as phytol, its isomer 3,7,11,15Tetramethyl-2-hexadecen-1-ol, Vitamins and hydrocarbons with anti-aging (anti-elastase, anti-collagenase, anti-hyaluronidase), antioxidant and anti-inflammatory properties thus exemplifying its significance as a source of cosmeceuticals [17]. The present study was designed to evaluate the effect of gamma radiation on the cosmeceutical potential of C. emersonii KJ725233 in terms of its pigment and antioxidant content.

\section{MATERIALS AND METHODS}

\section{Chemicals and reagents}

AR grade sodium hydroxide, hydrochloric acid, sulphuric acid, methanol, dimethyl sulpoxide Coomassie brilliant blue G-250, ethanol, o-phosphoric acid, bovine serum albumin, sodium dihydrogen phosphate, disodium hydrogen phosphate, ferric chloride, trichloroacetic acid, ascorbic acid, gallic acid, sodium carbonate, potassium ferricyanide, aluminium trichloride hydrate, quercetin and ammonium molybdate were obtained from SD FineChem Ltd, Mumbai. The plant grade chemicals required for BG-11 medium along with DPPH, folin-ciocalteau reagent were procured from HiMedia, Mumbai.

\section{Chlorella emersonii KJ725233 culturing and irradiation conditions}

$C E K$ was isolated from the western regions of Maharashtra and identified morphologically as well as by 18s rDNA sequencing [16]. CEK was grown in $1 \mathrm{~L} \mathrm{BG}-11$ and incubated at $34 \pm 1{ }^{\circ} \mathrm{C}$ with a lux intensity of $1000 \mathrm{X}$ for a period of $15 \mathrm{~d}$. At the end of incubation, this culture was equally distributed into three flasks, which were exposed to $\mathrm{Co}_{60}$ at a dose rate of $37.51 \mathrm{~Gy} \mathrm{~min}^{-1}$ for doses $100 \mathrm{~Gy}$ and 
1000 Gy in a GC5000 (BRIT) at the Department of Atomic Energy, BARC, Mumbai, India.

\section{Determination of chlorophyll content}

After irradiation, $10 \mathrm{ml}$ of theses cultures were drawn into preweighed centrifuge tubes. These were centrifuged at $5000 \mathrm{rpm}$ for $20 \mathrm{~min}$ and the supernatant was discarded. To the biomass, $10 \mathrm{ml}$ of methanol was added and chlorophyll extraction was carried out in an electric water bath at $60{ }^{\circ} \mathrm{C}$ for $2 \mathrm{~h}$. At the end of incubation, the absorbance of the supernatant was measured at 665 and $652 \mathrm{~nm}$. The chlorophyll content was determined by the following formulae $[18,19]-$

Chlorophyll a ( $\mu \mathrm{g} \mathrm{ml-1)}=16.72 *$ Absorbance (665)-9.16* Absorbance (652)

\section{Chlorophyll b ( $\mu \mathrm{g} \mathrm{ml-1)}=34.09 *$ Absorbance (652)-15.28* Absorbance (665)}

Preparation of CEK extracts for determination of the antioxidant potential

The dried biomass was suspended in absolute methanol at a concentration of $0.1 \mathrm{~g} \mathrm{ml}^{-1}$ and sonicated for $30 \mathrm{~min}$. These suspensions were centrifuged at $5000 \mathrm{rpm}$ for $20 \mathrm{~min}$ and the supernatants were transferred to three preweighed crucibles. The extraction was repeated thrice and the supernatants were pooled together. $1 \mu \mathrm{l}$ of these pooled supernatants were subjected to GCHRMS analysis for the identification of bioactives. The remaining supernatants were dried at $32 \pm 1{ }^{\circ} \mathrm{C}$ for $24 \mathrm{~h}$. The dried extracts were reconstituted in dimethyl sulfoxide and used for antioxidant studies.

\section{Antioxidant potential}

Total antioxidant capacity by phosphomolybdenum method [TAC]

The alterations in the total antioxidant capacity of CEK were determined by the phosphomolybdenum method as described earlier by Prieto et al. [20]. To $300 \mu \mathrm{l}$ of the extracts, $3 \mathrm{ml}$ of the total antioxidant capacity reagent $(0.6 \mathrm{mmol}$ sulphuric acid, $28 \mathrm{mmol}$ sodium phosphate and 4 mmol ammonium molybdate) was added and the reaction mixtures were incubated at $95{ }^{\circ} \mathrm{C}$ for $90 \mathrm{~min}$. At the end of incubation, the absorbance was measured at $695 \mathrm{~nm}$. Ascorbic acid was used as a standard and the total antioxidant capacity was expressed as mg ascorbic acid equivalence per g dry weight (mg AAE g-1 DW).

\section{Ferric reducing antioxidant potential [FRAP]}

The reducing potential was determined by using potassium ferricyanide by modifying the procedure as described earlier by Hemlatha et al. 21]. $125 \mu \mathrm{l}$ of $1 \%$ potassium ferricyanide was added to $50 \mu \mathrm{l}$ of the extract and incubated at $50{ }^{\circ} \mathrm{C}$ for $20 \mathrm{~min}$. After incubation, $125 \mu \mathrm{l}$ of $10 \%$ trichloroacetic acid was added and $100 \mu \mathrm{l}$ of this reaction mixture was transferred to fresh wells with an equal volume of distilled water. Finally, $20 \mu \mathrm{l}$ of $0.1 \%$ ferric chloride was added and the absorbance was measured at $700 \mathrm{~nm}$. Ascorbic acid was used as a standard and both the total antioxidant capacity (TAC) as well as the reducing potential (FRAP) was expressed as mg ascorbic acid equivalent per $\mathrm{g}$ dry weight ( $\mathrm{mg} \mathrm{AAE}^{-1} \mathrm{DW}$ ).

\section{DPPH radical scavenging potential}

The radical scavenging activity of the extracts was evaluated by DPPH (2, 2-Dipheny-1-picryl hydrazyl radical) assay by modifying the earlier reported procedure [22]. Methanol was used as a blank and ascorbic acid as a positive control. $150 \mu \mathrm{l}$ of $2 \%$ aluminium trichloride was added to an equal volume of varying concentrations of the extracts $\left(2-10 \mathrm{mg} \mathrm{ml}^{-1}\right)$ and incubated in the dark at $32 \pm 1{ }^{\circ} \mathrm{C}$ for $30 \mathrm{~min}$. After incubation the absorbance was read at $517 \mathrm{~nm}$. The free radical scavenging activity was then calculated as $\%$ inhibition by the following formula: $\left[\left(\mathrm{A}_{\text {(blank) }}-\mathrm{A}_{\text {(test) }}\right) / \mathrm{A}_{\text {(blank) }}\right] * 100$, where $\mathrm{A}_{\text {(test) }}$ is the absorbance of the extracts and $\mathrm{A}_{\text {(blank) }}$ is the absorbance of the blank. IC50 for the extracts was determined by plotting a graph of percentage inhibition against extract concentration. The tests were carried out in triplicates and the values were expressed as mean \pm SD.

\section{Total phenol content [TPC]}

The total phenolic content was determined by modifying the Folin's Ciocalteau method, as reported by Wu et al. [23]. To $25 \mu \mathrm{l}$ of the extracts, $50 \mu \mathrm{l}$ of $1 \mathrm{~N}$ Folin's Ciocalteau reagent was added followed with $125 \mu \mathrm{l}$ of $20 \%$ sodium carbonate was added. The reaction mixtures were incubated at $32 \pm 1{ }^{\circ} \mathrm{C}$ in the dark for $30 \mathrm{~min}$. The absorbance was read at $765 \mathrm{~nm}$. Gallic acid was used as a standard and the total phenolic content was expressed as mg gallic acid equivalence per $\mathrm{g}$ dry weight ( $\mathrm{mg} \mathrm{GAE} \mathrm{g}^{-1} \mathrm{DW}$ ).

\section{Total flavonoid content [TFC]}

To $150 \mu \mathrm{l}$ of the extracts, an equal volume of $2 \%$ aluminium trichloride was added and incubated in the dark at $32 \pm 1^{\circ} \mathrm{C}$ for 30 $\mathrm{min}$. At the end of incubation, the absorbance was measured at 415 $\mathrm{nm}$. Quercetin was used as a standard and the total flavonoid content was expressed as mg quercetin equivalence per g dry weight (mg QE g-1 DW) [24].

Determination of radiation-induced alterations in bioactives of CEK by gas chromatography-high resolution mass spectrometry

GC-HRMS analysis was carried out using Agilent Technologies GC equipped with Accutoff MS. Bioactives were separated on HP-5 MS capillary column having $5 \%$ phenyl polysiloxane as stationary phase, column length $30 \mathrm{~m}$, internal diameter $0.32 \mathrm{~mm}$ and film thickness $0.25 \mu \mathrm{m} .1 \mu \mathrm{l}$ of the sample was injected in the split ratio of $10: 1$, the injector and transfer line temperature was $250^{\circ} \mathrm{C}$ and $260{ }^{\circ} \mathrm{C}$ while the ion source temperature was $200{ }^{\circ} \mathrm{C}$. Oven temperature programmed from 80 to $280^{\circ} \mathrm{C}$ at $10^{\circ} \mathrm{C}$ min-1; flow rate of carrier gas helium was $1 \mathrm{ml} \mathrm{min}^{-1}$. Essential compounds were identified comparing their retention times and mass fragmentation patterns with the data of standards at the National Institute of Standards and Technology (NIST) library [22].

\section{RESULTS AND DISCUSSION}

\section{Effect of gamma radiation on the chlorophyll content of $C E K$}

The quantitative shift in the total chlorophyll content in $C E K$ on irradiation was determined spectrophotometrically and an increase of $179.57 \pm 2.55 \%$ was observed in $C E K$ irradiated at 1000 Gy (fig. 1). An alteration in the chlorophyll content is one of the preliminary indicators of the mutagenic effects of gamma irradiation [25]. Gamma radiation is reported to induce photoluminescence [26] which can be due to a corresponding increase in chlorophyll content. In addition to an increase in the total chlorophyll content, an alteration in the chlorophyll $\mathrm{a}$ : chlorophyll $\mathrm{b}$ ratio from $1: 2$ in the control to 1:1 was observed on irradiation. This shift in the chlorophyll a: chlorophyll $b$ ratio on radiation might be due to a reduction in chlorophyll b synthesis at a higher radiation dose [4].

\section{Quantitative effect of gamma radiation on the antioxidant content of $C E K$}

The quantitative alterations in the antioxidant potential of $C E K$ as a response to gamma radiation were determined in terms of total antioxidant capacity, ferric reducing antioxidant potential and DPPH radical scavenging potential together with modulations in the total phenolic and total flavonoid content. A $71.76 \pm 2.96 \%, 32.08 \pm 2.16 \%$, $11.67 \pm 0.89 \%, 42.85 \pm 8.0 \%$ and $31.37 \pm 3.18 \%$ increase was observed in the total antioxidant capacity, ferric reducing antioxidant potential, radical scavenging potential ( $\mathrm{IC}_{50}$ ), total phenol and flavonoid content respectively in $1000 \mathrm{~Gy}$ irradiated CEK as compared to non-irradiated $C E K$ (fig. 2a).

Gamma rays are known to interact with the cellular molecules thereby inducing the generation of free radicals such as ROS and RNS. This oxidative stress is counteracted by cellular enzymatic and non-enzymatic antioxidant defense systems $[27,28]$. Literature also suggests a positive correlation between FRAP and Phosphomolybdenum assay with superoxide dismutase (SOD), catalase (CAT) and peroxidase activity (POD); wherein an increase in the antioxidant capacity of Monodora myristica was observed with a corresponding increase in the antioxidant enzyme activity [29]. The increase in antioxidant potential obtained in the present study thus could be due to enhanced expression of these antioxidant enzymes since gamma radiation is reported to stimulate antioxidant enzymes such as SOD, CAT, POD and polyphenol oxidase (PPO). Besides these enzymatic antioxidants, the phosphomolybdenum 
method measures non-enzymatic antioxidants such as ascorbic acid, phenols, $\alpha$-tocopherols, carotenoids and reduced glutathione [30].

Although dramatic induction of total antioxidant capacity was observed, an increase in antioxidant potential as measured by FRAP was modest but significant as seen in fig. 2a. Both 100 Gy and 1000 Gy caused an increase in the range of $30 \%$ and it possibly indicates saturation in the antioxidant species as measured by FRAP. Radical scavenging ability is seen in fig. $2 \mathrm{~b}$ does not show significant alterations in response to radiation, while total phenolics increased marginally under similar treatment conditions. Only water-soluble antioxidants are measured by FRAP [31] therefore, an increase in reducing power obtained in the present study can thus be mainly attributed to a corresponding increase in the hydrophilic antioxidants. Also, the reducing power obtained at 1000 Gy i.e. $15.86 \pm 0.7 \mathrm{mg} \mathrm{AAE} \mathrm{g}^{-1} \mathrm{DW}$ was more than twenty and sixteen folds higher than that reported for the methanolic extract of Chlorella marina and Chlorella salina respectively [21, 32].

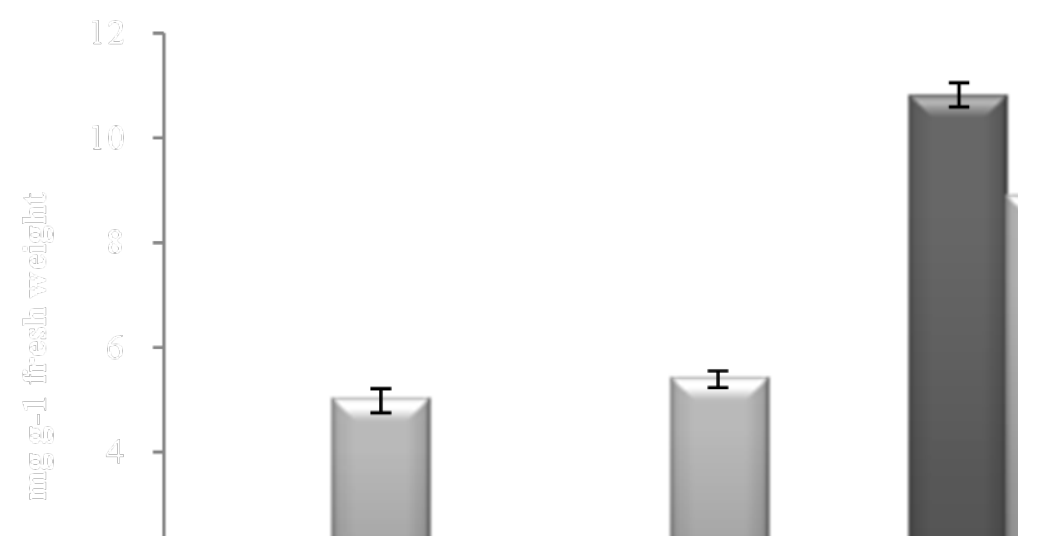

Fig. 1: Effect of gamma radiation doses $(100 \mathrm{~Gy}$ and $1000 \mathrm{~Gy}$ ) on the chlorophyll content of $C E K$. The data is expressed as mean $\pm \mathrm{SD}(\mathrm{n}=3$ )

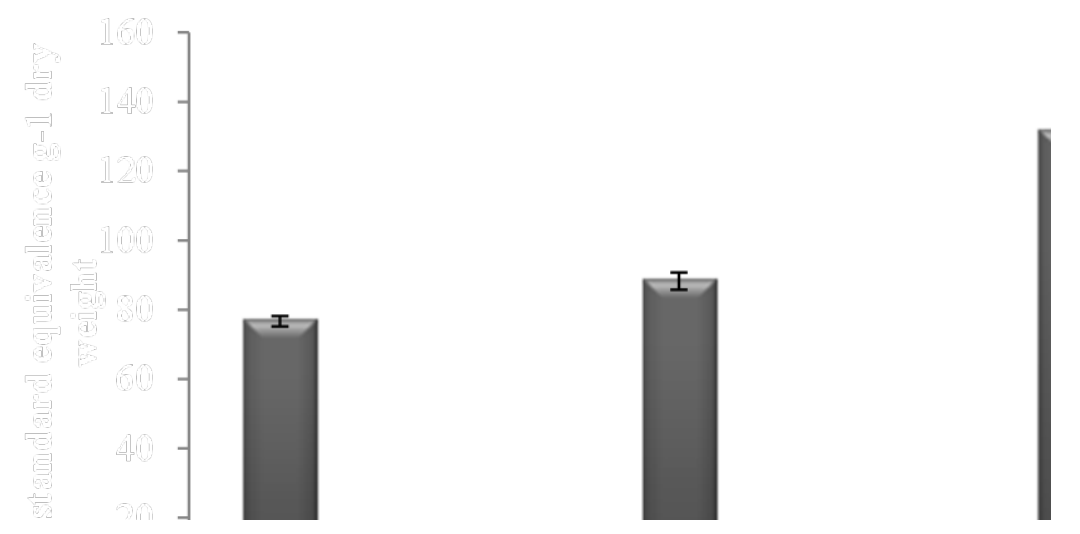

Fig. 2a: Antioxidant potential of non-irradiated $C E K$ (control); $100 \mathrm{~Gy}$ and $1000 \mathrm{~Gy}$ irradiated $C E K$ in terms of TAC, FRAP and TPC. The data is expressed as mean \pm SD $(n=3)$
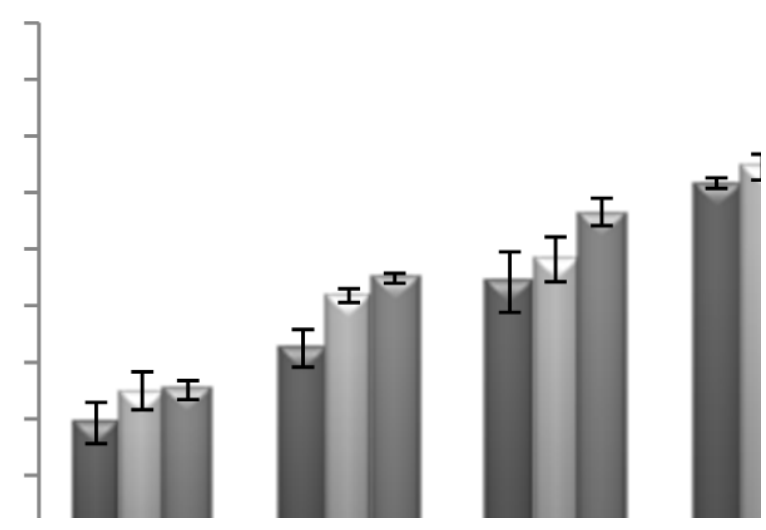

Fig. 2b: Radical scavenging potential of non-irradiated $C E K$ (control), $100 \mathrm{~Gy}$ and $1000 \mathrm{~Gy}$ irradiated $C E K$. The data is expressed as mean $\pm S D(n=3)$ 
Phenolic content was determined by Folin's Ciocalteau method which measures only the hydrophilic phenols [21]. The improved phenolic content on irradiation may be attributed to the increase in the activity of phenylalanine ammonia-lyase an enzyme directly involved in the phenol synthesis [33]. Since Vitamin C used as a standard was a commercially purified product, the radical scavenging activity $\left(\mathrm{IC}_{50}\right)$ for irradiated as well as non-irradiated $C E K$ both were found to be lower than Vitamin C i.e. $6.47 \pm 0.89 \mu \mathrm{g} \mathrm{ml}$ ${ }^{1}$ (data not represented). However, the $\mathrm{IC}_{50}$ for 100 Gy irradiated alga was lower than that reported for the commercially available tablets of Chlorella pyrenoidosa (Sun Chlorella) which is $9.62 \mathrm{mg} \mathrm{ml}^{-1}$ [34]. Though an increase in the phenolic content was observed, no significant change was detected in the radical scavenging activity for the given radiation doses. DPPH has been widely used for measuring the antioxidant status of phenolic compounds; however, only lipophilic antioxidants are measured by DPPH whereas the method used in the present study to detect the phenolic content evaluated only the hydrophilic antioxidants [21].

\section{Qualitative alterations in the bioactives of $C E K$ as a response to} gamma radiation

GC-HRMS analysis was performed to identify the pattern of metabolite induction as a response to low and high doses of gamma radiation that could have eventually influenced the antioxidant potential in CEK. The compounds identified along with their percentage areas were shown in table 1. The GC-HRMS analysis revealed a spectrum of ten different compounds belonging to the varying classes predominantly in the category of alcohols, hydrocarbons, sterols and fat-soluble vitamin.

Phytol was one of the two compounds which presented quantitative changes which decreased from a concentration of $71.7 \%$ to $27.18 \%$ at $100 \mathrm{~Gy}$ and then increased to $34.17 \%$ at $1000 \mathrm{~Gy}$. Both phytol and its isomer 3,7,11,15-tetramethyl-2-hexadecen-1-ol are known to possess antimicrobial, antioxidant and anti-inflammatory activities. These have been used in the production of synthetic forms of Vitamin E and Vitamin K1 [35-37]. Phosphorylation of phytol to phytyl-phosphate and phytyl-diphosphate further feeds into the tocopherol synthesis pathway [38]. It might be the result of channelization of phytol into tocopherol synthesis that led to reduced phytol levels in the irradiated $C E K$ as compared to the nonirradiated. As seen in table 2, Vitamin E a known free radical scavenger exhibited quantitative induction on irradiation at 100 and 1000 Gy. Naturally occurring Vitamin E consists of both saturated forms (tocopherols) as well as unsaturated forms (tocotrienols). Tocopherols are reported to be one of the two best chain-breaking phenolic antioxidant groups whereas tocotrienols are known to be potent antioxidants, antibacterial, anti-inflammatory, anticancer, hepatoprotective and hypoglycemic [39-41]. Vitamin E along with Vitamin C is one of the most sought after antioxidants in dermatology with most of the over-the-counter anti-aging creams containing 0.5-1\% Vitamin E [42].

The increased antioxidant potential of $C E K$ on irradiation can also be attributed to a shift from a $\mathrm{C}_{10}$ compound (1-Iodo-2-methyl nonane) to $\mathrm{C}_{16}$ compound (Hexadecane); hexadecane is also reported to be an antioxidant as well as an antibacterial [43].

Table 1: Alterations in bioactives of $C E K$ as a response to gamma radiation

\begin{tabular}{|c|c|c|c|c|}
\hline $\begin{array}{l}\text { S. } \\
\text { No. }\end{array}$ & $\begin{array}{l}\text { Retention time } \\
\text { (min) }\end{array}$ & Non-irradiated & $100 \mathrm{~Gy}$ & 1000 Gy \\
\hline 1 & 18.76 & 1-Iodo-2-methylnonane (5.70\%) & Hexadecane $(1.17 \%)$ & Hexadecane (2.11\%) \\
\hline \multirow[t]{2}{*}{2} & 21.26 & - & $\begin{array}{l}\text { 3,7,11,15-Tetramethyl-2-hexadecen- } \\
\text { 1-ol (1.67\%) }\end{array}$ & $\begin{array}{l}\text { 3,7,11,15-Tetramethyl-2- } \\
\text { hexadecen-1-ol (1.39\%) }\end{array}$ \\
\hline & 21.27 & $\begin{array}{l}\text { Cis-13,15-docasadienoic acid, methyl } \\
\text { ester }(1.72 \%)\end{array}$ & - & - \\
\hline 3 & 22.00 & - & $\begin{array}{l}\text { 3,7,11,15-Tetramethyl-2-hexadecen- } \\
\text { 1-ol (1.54\%) }\end{array}$ & - \\
\hline 4 & 22.01 & $\begin{array}{l}\text { 3,7,11,15-Tetramethyl-2-hexadecen- } \\
\text { 1-ol (4.88\%) }\end{array}$ & - & $\begin{array}{l}\text { 3,7,11,15-Tetramethyl-2- } \\
\text { hexadecen-1-ol (2.24\%) }\end{array}$ \\
\hline 5 & 26.85 & - & Phytol (27.18\%) & - \\
\hline 6 & 26.86 & - & - & Phytol (34.17\%) \\
\hline 7 & 26.88 & Phytol (71.50\%) & - & - \\
\hline 8 & 29.34 & - & $\begin{array}{l}\text { Cholesta-6,22,24-triene-4,4-dimethyl } \\
(9.87 \%)\end{array}$ & - \\
\hline 9 & 30.51 & - & Stigmastan-3,5-diene (30.64\%) & - \\
\hline 10 & 31.61 & - & Tert-Hexadecanethiol (5.06\%) & - \\
\hline 11 & 31.62 & 1,2-Octadecanethiol (15.11\%) & - & - \\
\hline 12 & 31.63 & - & - & 1-Docosene $(8.12 \%)$ \\
\hline 13 & 32.23 & - & Campesterol (2.54\%) & - \\
\hline 14 & 32.74 & - & Vitamin E $(17.97 \%)$ & - \\
\hline 15 & 32.84 & - & 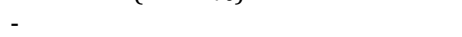 & Vitamin E (46.67\%) \\
\hline
\end{tabular}

Irradiation also induced the synthesis of sterols such as Cholesta6,22,24-triene-4,4-dimethyl, stigmastan-3,5-diene and campesterol at low dose as seen in table 1 . The induction of sterols might be a protective response of the alga to resist the harmful effects of radiation. Similar results have been reported [44] in Cryptococcus neoformans. However, at higher radiation doses there was a marked absence of sterols. Higher gamma radiation doses have reported to repress the genes coding for enzymes involved in isoprenoid and sterol synthesis in Trypanosoma cruzi [45]. The percent increase in the antioxidant activity of 100 Gy and 1000 Gy irradiated alga could, therefore, be related to the induction of Vitamin $\mathrm{E}$ as well as hexadecane as identified in the corresponding extracts as observed in table 1.

\section{CONCLUSION}

The present study clearly indicated that gamma radiation causes significant qualitative as well as quantitative alterations in the composition of bioactive compounds which subsequently modulates the biological activities of the alga. Manipulation of the physical environment of $C$. emersonii KJ725233 induced the synthesis of cosmeceutically significant Vitamin E. By far chemical synthesis and extraction from vegetable oils are the only commercial sources of Vitamin E. Hence its elevated synthesis by the alga in response to irradiation makes it a potential approach for scale-up of such an essential anti-aging compound and opens up the possibility of its use as a novel cost-effective source of cosmeceuticals.

\section{AUTHORS CONTRIBUTIONS}

All authors have contributed equally. Sneha Sawant and Reema Devi Singh have performed the experiments, Sneha Sawant has drafted the manuscript. Sukhendu Ghosh and Varsha Kelkar Mane have contributed in experiment designing and manuscript editing. 


\section{CONFLICT OF INTERESTS}

The authors declare no conflict of interest

\section{REFERENCES}

1. Pancha I, Chokshi K, George B, Ghosh T, Paliwal C, Maurya R, et al. Nitrogen stress-triggered biochemical and morphological changes in the microalgae Scenedesmus sp. CCNM 1077. Bioresour Technol 2014;156:146-54.

2. Gacheva GV, Gigova LG. Biological activity of microalgae can be enhanced by manipulating the cultivation temperature and irradiance. Cent Eur J Biol 2014;9:1168-81.

3. Campos H, Boeing WJ, Dungan BN, Schaub T. Cultivating the marine microalga Nannochloropsis salina under various nitrogen sources: effect on biovolume yields, lipid content and composition, and invasive organisms. Biomass Bioenergy 2014;6:2-8.

4. Marcu D, Damian G, Cosma C, Cristea V. Gamma radiation effects on seed germination, growth and pigment content, and ESR study of induced free radicals in maize (Zea mays). J Biol Phys 2013;39:625-34.

5. Rahman K. Studies on free radicals, antioxidants, and cofactors. Clin Interv Aging 2007;2:219-36.

6. Kebeish R, Hanan ED, Nagwa E. Effect of gamma radiation on growth, oxidative stress, antioxidant system and allin producing gene transcripts in Allium sativum. Int J Res Stud Biosci 2015;3:161-74.

7. Zahran AA, Eliwa NE. Influence of gamma radiation, glutathione and ascorbic acid on some antioxidant enzymes in Egyptian clover (Trifolium alexandrinum L.) under aluminium stress. Am Emras J Agric Environ Sci 2015;15:1887-94.

8. Tale MP, Devi SR, Kapadnis BP, Sukhendu BG. Effect of gamma irradiation on lipid accumulation and expression of regulatory genes involved in lipid biosynthesis in Chlorella species. J Appl Phycol 2017. https://doi.org/10.1007/s10811-017-1229-9.

9. Abomohra AEF, El-Shouny W, Sharaf M, Abo-eleneen M. Effect of gamma radiation on growth and metabolic activities of Arthrospira platensis. Braz Arch Biol Technol 2016;59:1-12.

10. Marathe SA, Deshpande R, Khamesra A, Ibrahim G, Jamdar SN. Effect of radiation processing on nutritional, functional, sensory and antioxidant properties of red kidney beans. Radiat Phys Chem 2016;125:1-8.

11. Iglesias Andreu L, Octavio Aguilar P, Bello Bello J. Current importance and potential use of low doses of gamma radiation in forest species. In: Adrovic F. (Ed.) Gamma Radiation InTech; 2012. p. 263-80.

12. Pimentel FB, Alves RC, Rodrigues F, Oliveira MBPP. Macroalgae-derived ingredients for the cosmetic industry-an update. Cosmetics 2018;5:1-18.

13. Paschinger $H$, Vanicek $T$. Effect of gamma irradiation on two mechanisms of Rb (K) uptake by Chlorella. Rad Bot 1974;14:301-7.

14. Vershina LK, Sakorich IS, Shevchenko VA. Effect of gamma radiation on chlorella at different stages in the cell cycle. Kosm Biol Aviak Med 1976;10:79-80.

15. Sawant SS, Kelkar Mane V. Nutritional profile, antioxidant, antimicrobial potential, and bioactive profile of Chlorella emersonii KJ725233. Asian J Pharm Clin Res 2018;11:220-5.

16. Sawant SS, Joshi AA, Bhagwat AA, Kelkar Mane V. Tapping the antioxidant potential of a novel isolate-Chlorella emersonii. World J Pharm Res 2014;3:726-39.

17. Sawant SS, Kelkar Mane V. Correlating the anti-aging activity with the bioactive profile of $C$. emersonii KJ725233; its toxicological studies for potential use in cosmeceuticals. Phcog Commn 2017;7:152-7.

18. Henriques M, Silva A, Rocha J. Extraction and quantification of pigments from a marine microalga: a simple and reproducible method. In: Mendez Vilas A. editor. Communicating Current Research and Educational Topics and Trends in Applied Microbiology. Vol 1. Spain: Formatex; 2007. p. 586-93.

19. Lichtenthaler HK, Buschmann C. Chlorophylls and carotenoids: measurement and characterization by UV-VIS spectroscopy. In: Current Protocols in Food Analytical Chemistry. USA: John Wiley and Sons, Inc; 2001. p. F4.3.1-8.

20. Prieto P, Pineda M, Aguilar M. Spectrophotometric quantitation of antioxidant capacity through the formation of a phosphor- molybdenum complex: specific application to the determination of vitamin E. Anal Biochem 1999;269:337-41.

21. Hemalatha A, Girija K, Parthiban C, Saranya C, Anantharaman P. Antioxidant properties and total phenolic content of a marine diatom, Navicula clavata and green microalgae, Chlorella marina and Dunaliella salina. Adv Appl Sci Res 2013;4:151-7.

22. Bendaoud H, Bouajila J, Rhouma A, Savagnac A, Romdhane M. GC/MS analysis and antimicrobial and antioxidant activities of essential oil of Eucalyptus radiata. J Sci Food Agric 2009;89:1292-7.

23. Wu LC, Ho JA, Shieh MC, Lu IW. Antioxidant and antiproliferative activities of Spirulina and Chlorella water extracts. J Agric Food Chem 2005;53:4207-12.

24. Velvizhi S, Annapurani S. Estimation of total flavonoid, phenolic content and free radical scavenging potential of Glycyrrhiza glabra root extract. Asian J Pharm Clin Res 2018;11:231-5.

25. Mohajer S, Taha RM, Lay MM, Esmaeili AK, Khalili M. Stimulatory effects of gamma irradiation on phytochemical properties, mitotic behavior and nutritional composition of sainfoin (Onobrychis vicifolia Scop.). Sci World J 2014:1-9. http://dx.doi.org/10.1155/2014/854093.

26. Fu JS, Mao JC, Wu E, Jia YQ, Zhang BR, Zhang LZ, et al. Gamma-rays irradiation: an effective method for improving light emission stability of porous silicon. Appl Phys Lett 1993;63:1830-2.

27. Ali H, Ghori Z, Sheikh S, Gul A. Effect of gamma radiation on crop production. In: Hakeem KR. editor. Crop Production and Global Environmental Issues. Cham: Springer; 2015. p. 27-78.

28. Reisz JA, Bansal N, Qian J, Zhao W, Furdui CM. Effects of ionizing radiation on biological molecules-mechanisms of damage and emerging methods of detection. Antiox Redox Signal 2014;21:260-92.

29. Moukette BM, Pieme CA, Nijmou JR, Biapa CPN, Marco B, Ngogang JY. In vitro antioxidant properties, free radical scavenging activities of extracts and polyphenol composition of a non-timber forest product used as spice: Monodora myristica. Biol Res 2015;48:1-17.

30. Pal RS, Kumar AR, Agrawal PK, Bhatt JC. Antioxidant capacity and related phytochemical analysis of a methanolic extract of two wild edible fruits from Northwestern Indian Himalaya. Int J Pharm Biol Sci 2013;4:113-23.

31. Apak RK, Guclu K, Demirata B, Ozyurek M, Celik S, Bektasoglu $\mathrm{B}$, et al. Comparative evaluation of various total antioxidant capacity assays applied to phenolic compounds with the CUPRAC assay. Mol 2007;12:1496-547.

32. Saranya C, Hemalatha A, Parthiban C, Anantharaman P. Evaluation of antioxidant properties, total phenolic and carotenoid content of Chaetoceros calcitrans, Chlorella salina and Isochrysis galbana. Int J Curr Microbiol Appl Sci 2014;3:365-77.

33. Fernandes A, Antonio AL, Oliveria MBP, Martins A, Ferreira IC. Effect of gamma and electron beam irradiation on the Physicochemical and nutritional properties of mushrooms: a review. Food Chem 2012;135:641-50.

34. Geetha BV, Navasakthi R, Padmini E. Investigation of antioxidant capacity and phytochemical composition of sun chlorella-an in vitro study. J Aqua Res Dev 2010;1:1-7.

35. Suffo KL, Ashish R, Pamo TE, Kuiate JR. Effect of processing methods on chemical composition and antioxidant activities of two amaranthus sp. harvested in the west region of cameroons. J Nutr Food Sci 2016;6:1-9.

36. Santos CCMP, Salvadori M, Mota VG, Costa LM, Almeida AAC, Oliveira GAL, et al. Antinociceptive and antioxidant activities of phytol in vivo and in vitro. Neurosci J 2013:1-9. http://dx.doi.org/10.1155/2013/949452.

37. Venkat RB, Samuel LA, Paradha SM, Narashimha RB, Radhakrishnan TM. Antibacterial, antioxidant activity and GCMS analysis of Eupatorium odoratum. Asian J Pharm Clin Res 2012;5:99-106.

38. Dorp KV, Holzl G, Plohmann C, Eisenhut M, Abraham M, Weber APM, et al. Remobilization of phytol from chlorophyll degradation is essential for tocopherol synthesis and growth of arabidopsis. Plant Cell 2015;27:2846-59.

39. Sen KC, Rink C, Khanna S. Palm oil-derived natural Vitamin E $\alpha$ tocotrienol in brain health and diseases. J Am Coll Nutr 2010;29:314S-23S. 
40. Engin KN. Alpha-tocopherol: looking beyond an antioxidant. Mol Vis 2009;15:855-60.

41. Wu SJ, Lui PL, Ng LT. Tocotrienol-rich fraction of palm oil exhibits anti-inflammatory property by suppressing the expression of inflammatory mediators in human monocytic cells. Mol Nutr Food Res 2008;52:921-9.

42. Keen MA, Hassan I. Vitamin E in dermatology. Indian Dermatol Online J 2016;7:311-4

43. Rajendran N, Karpanai SB, Sobana PP, Logeswari V, Kathiresan E, Tamilselvi A, et al. Phytochemicals, antimicrobial and antioxidant screening from five different marine microalgae. J Chem Pharm Sci 2014:Suppl:78-85.

44. Jung KW, Yang DH, Kim MK, Seo HS, Lim S, Bahn YS. Unraveling fungal radiation resistance regulatory networks through genome-wide transcriptome and genetic analyses of Cryptococcus neoformans. mBio 2016:7:1-15.

45. Grynberg P, Passos Silva DG, Mourao MM, Roberto $\mathrm{H}$, Macedo AM, Machado CR, et al. Trypanosoma cruzi gene expression in response to gamma radiation. PLoS One 2012;7:1-14. 